\title{
Pip, a lymphoid-restricted IRF, contains a regulatory domain that is important for autoinhibition and ternary complex formation with the Ets factor PU.1
}

\author{
Abraham L. Brass, ${ }^{1,2}$ Eli Kehrli, ${ }^{1}$ Charles F. Eisenbeis, ${ }^{2}$ Ursula Storb, ${ }^{2}$ and Harinder Singh ${ }^{1,2,3}$ \\ ${ }^{1}$ Howard Hughes Medical Institute and ${ }^{2}$ Department of Molecular Genetics and Cell Biology, The University of Chicago, \\ Chicago, Illinois 60637 USA
}

Pip is a lymphoid-restricted IRF transcription factor that is recruited to composite elements within immunoglobulin light-chain gene enhancers through a specific interaction with the Ets factor PU.1. We have examined the transcriptional regulatory properties of Pip as well as the requirements for its interaction with PU.1 and DNA to form a ternary complex. We demonstrate that Pip is a dichotomous regulator; it specifically stimulates transcription in conjunction with PU.1, but represses $\alpha / \beta$-interferon-inducible transcription in the absence of PU.1. Thus, during B-cell activation and differentiation, Pip may function both as an activator to promote B cell-specific gene expression and as a repressor to inhibit the antiproliferative effects of $\alpha / \beta$-interferons. Mutational analysis of Pip reveals a carboxy-terminal segment that is important for autoinhibition of DNA binding and ternary complex formation. A domain of Pip containing this segment confers autoinhibition and PU.1-dependent binding activity to the DNA-binding domain of the related IRF family member, $\mathrm{p} 48$. On the basis of these and other data we propose a model for PU.1/Pip ternary complex formation.

[Key Words: Immunoglobulin; transcription factor; IRF; Ets; ternary complex]

Received June 13, 1996; revised version accepted July 24, 1996.

Eukaryotic promoters and enhancers contain multiple transcription factor binding sites, resulting in the assembly of hetero-oligomeric protein-DNA complexes (Maniatis et al. 1987; McKnight and Yamamoto 1992). Specific protein-protein interactions among transcription factors contribute to the specificity of gene regulation by these complexes. Examples of such interactions include the tethering of the viral coactivator VP16 to DNA via interactions with the cellular proteins Oct-1 and host cell factor (HCF; Kristie et al. 1989; Katan et al. 1990), the mutually dependent binding of the yeast transcription factors MAT $\alpha 1$ and MCM1 to upstream regulatory regions of $\alpha$-cell-type-specific genes (Bender and Sprague 1987), and the recruitment of the Ets protein, SAP-1, to the serum-response element of the c-fos promoter by the serum-response factor (SRF; Dalton and Treisman 1992). In each of these examples, the specificity of transcriptional control depends on context-dependent modulation of transcription factor activity via both proteinDNA and protein-protein interactions. Elucidating the mechanism of promoter- and enhancer-mediated transcriptional regulation, therefore, depends on understanding both types of interactions.

${ }^{3}$ Corresponding author.
The cell-type- and developmental-stage-specific transcriptional activity of heavy- and light-chain immunoglobulin (Ig) genes is regulated by a set of cell-type-specific and ubiquitously expressed transcription factors that bind to promoter and enhancer elements (Staudt and Lenardo 1991). These transcription factors may also play a role in controlling $V(D) I$ recombination, as mutations in enhancer elements impair Ig gene rearrangement (Serwe et al. 1993; Xu et al. 1996). The interacting transcription factors PU.1 and Pip are implicated as regulators of Ig light-chain gene expression. Pip (PU.1 interaction partner) is recruited to a cell-type-specific composite element contained within the Ig light-chain gene enhancers $E_{\kappa 3^{\prime}}, E_{\lambda 2-4}$ and $E_{\lambda 3-1}$ through specific interactions with PU.1 (Eisenbeis et al. 1995). Pip likely represents the cell-type-specific transcription factor, NF-EM5 (Pongubala et al. 1992; Eisenbeis et al. 1993). Pip is also referred to as LSIRF (Matsuyama et al. 1995) and ICSAT (Yamagata et al. 1996). The transcription factor PU.1, a member of the Ets family (Klemsz et al. 1990), is essential for the development of lymphoid and myeloid lineages (Scott et al. 1994; Olson et al. 1995). PU.1 and Pip bind immediately adjacent sites within the composite element, and mutation of either binding site has been shown to abolish enhancer function (Judde and Max 
1992; Eisenbeis et al. 1993|. Whereas PU.1 binds DNA independently, the binding of Pip is dependent on the presence of DNA-bound PU.1 that is phosphorylated on serine residue 148 (Pongubala et al. 1993; Eisenbeis et al. 1995). When coexpressed in NIH-3T3 cells, PU.1 and Pip function as mutually dependent coactivators of a reporter gene containing the composite element (Eisenbeis et al. 1995). Recent experiments have shown that mutation of the PU.1-binding site within the $\mathrm{E}_{\mathrm{k} 3}$, enhancer abolishes the cell type- and developmental stage-specific recombination of a $\mathrm{k}$ transgene (Hiramatsu et al. 1995). Together these facts suggest that PU.1 and Pip may function in controlling both the transcriptional activity and the recombinational specificity of Ig light-chain genes.

On the basis of sequence homology, Pip belongs to the interferon-regulatory-factor (IRF) family and its expression is lymphoid-restricted (Eisenbeis et al. 1995). IRFs possess a conserved amino-terminal DNA-binding domain, and upon interferon (IFN) treatment of cells, IRFs modulate the expression of genes containing an IFNstimulated response element (ISRE; for review, see Taniguchi et al. 1995). The prototypical members of the IRF family, IRF-1 and IRF-2 (Harada et al. 1989), are ubiquitously expressed and function as an activator (IRF-1) and a repressor (IRF-2) of IFN-inducible gene expression. Among the IRFs, Pip is most closely related in sequence to the interferon consensus sequence-binding protein (ICSBP) and p48/ISGF3 $\gamma$. The DNA-binding domain of Pip exhibits $83 \%$ and $51 \%$ amino acid identity with equivalent domains of ICSBP and p48, respectively. In addition, Pip shows similarity with ICSBP and p48 at comparable positions within their respective carboxyl termini (Eisenbeis et al. 1995; Matsuyama et al. 1995). ICSBP is a lymphoid-myeloid restricted repressor of IFN-inducible transcription (Driggers et al. 1990; Nelson et al. 1993) and, like Pip, is recruited to the Ig light-chain composite element by PU.1 (Eisenbeis et al. 1995). The functional significance of this interaction, however, is not known. p48 is a widely expressed subunit of the $\alpha / \beta$ IFN-inducible, STAT-containing transcription factor complex ISGF3, which binds to ISREs and activates transcription (Veals et al. 1992; for review, see Schindler and Darnell 1995). Although p48 is capable of binding independently to an ISRE, its binding affinity is greatly increased by protein-protein interactions with STAT1 and STAT2. Together with the PU.1-dependent binding requirements of Pip and ICSBP, this suggests that structurally distinct transcription factors, such as PU.1 or STATs, may utilize a common mechanism for regulating the DNA binding activities of the IRFs: Pip, ICSBP, and $\mathrm{p} 48$.

\section{Results}

\section{Pip is NF-EM5}

The B cell-restricted factor, NF-EM5, binds to composite elements within $E_{\kappa 3}$, or $E_{\lambda 2-4}$ in a PU.1-dependent manner (Pongubala et al. 1992; Eisenbeis et al. 1993). In a gel mobility shift assay with nuclear extract from J558L cells (a $\lambda 1$-producing murine myeloma), three specific protein-DNA complexes, JB1, JB2, and JB3, are formed on a probe containing the $E_{\lambda 2-4}$ composite element $(\lambda B$; Eisenbeis et al. 1993; Fig. 1A, lane 10). Previously, the JB2 complex has been shown to contain PU.1 and NFEM5, which bind cooperatively to the $\lambda B$ site (Eisenbeis et al. 1993). To determine if the protein encoded by the Pip gene is NF-EM5, we generated antibodies against a glutathione $S$-transferase (GST) fusion protein, containing full-length Pip (see Materials and Methods). Preincubation of preimmune serum with in vitro transcribed and translated (IVT) PU.1 alone, PU.1 and Pip, or J558L nuclear extract (Fig. 1A, lanes 3,7,11) had no effect on any of the complexes. In the presence of anti-PU.1 antiserum, the JB2 complex was supershifted, confirming the presence of PU.1 in JB2 (Fig. 1A, lane 12). Preincubation of the J558L extract with anti-Pip antiserum (Fig. 1A, lane 13) also resulted in a supershift of JB2, as well as the appearance of a new faster migrating band, with the same relative mobility as IVT PU.1 (Fig. 1A, cf. lanes 2 and 13). Identical results were obtained with complexes generated with a $\mathrm{E}_{\mathrm{\kappa} 3}$, composite element probe /data not shown). It should be noted that the JB3 complex, which has been shown to have an identical footprint to JB2 (Eisenbeis et al. 1993), was also supershifted with the anti-PU.1 and anti-Pip antisera and, thus, may consist of proteolyzed or modified forms of PU.1 and/or Pip. Importantly, the anti-Pip antiserum did not cross-react with ICSBP (see Fig. 1B). Furthermore, gel mobility shift assays involving anti-ICSBP antiserum revealed that ICSBP was not present at a detectable level in complexes from J558L extracts (C. Eisenbeis, U. Storb, and H. Singh, unpubl.). Thus, Pip is NF-EM5 and is the predominant factor associating with PU.1 on the $\lambda$ and $\kappa$ enhancer segments in J558L cells.

To assess the expression levels of Pip in B lineage cells, we performed Western analysis with anti-Pip antiserum. Pip protein was detected in cell lines representing pre-B (wt-bcl2-3), immature-B (WEHI-231), mature-B (A20) and plasmacyte (J558L) stages of B-cell development, with expression increasing in later-stage cells (Fig.1B). The prominent lower bands may represent Pip isoforms or degradation products. In support of the former possibility, three different Pip transcripts are detected in latestage B-cell lines (Eisenbeis et al. 1995). No expression of Pip was detected in fibroblast (NIH-3T3) or erythroid (MEL-201) cells. As noted earlier, the anti-Pip antiserum was not cross-reactive with either ICSBP or $\mathrm{p} 48$.

Because our earlier studies demonstrated that Pip is dependent on PU.1 for both DNA-binding and transcriptional activation, we investigated whether Pip localization to the nucleus also required PU.1. We assessed the subcellular localization of an epitope-tagged derivative of Pip (HAPip) by performing indirect immunofluorescence and DAPI nuclear staining of transiently transfected NIH-3T3 cells (Fig. 1C, left and center panels, respectively). These cells do not express PU.1 (Galson et al. 1993). Superpositioning of the images revealed that Pip localizes to the nucleus in the absence of PU.1, strongly suggesting that Pip contains a nuclear localization signal 
A

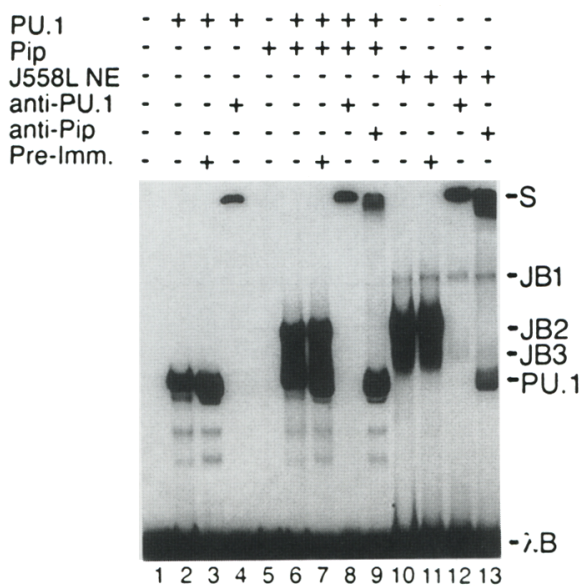

B

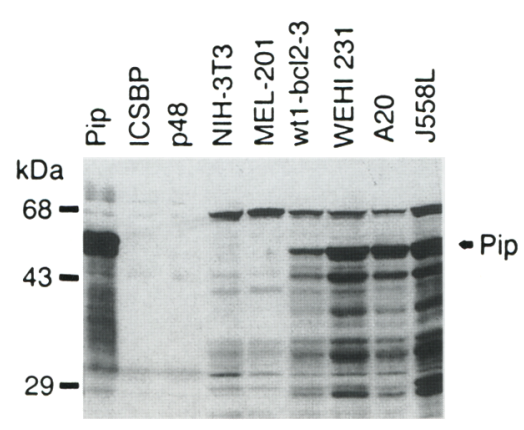

TAAAAGGAAGTGAAACCAAG $\lambda B$ PU.1 Pip

C

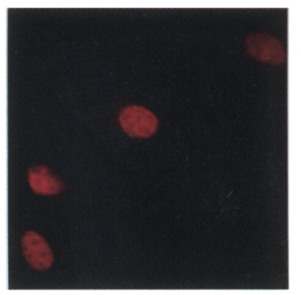

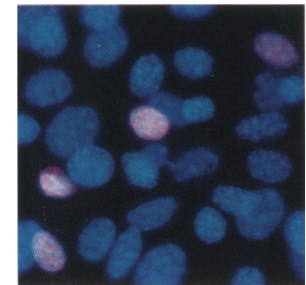

Figure 1. Pip is NF-EM5 and localizes to the nucleus independently of PU.1. (A) Gel mobility shift analysis of complexes formed on the $\lambda B$ site probe. (Lane 1) No protein; (lanes 2-4) IVT PU.1 alone (2), or with preimmune rabbit serum (3), or with anti-PU.1 antiserum (4); (lane 5) IVT Pip alone; (lanes 6-9) IVT PU.1 and Pip alone (6), or with preimmune serum (7), or with anti-PU.1 antiserum (8), or with anti-Pip antiserum (9); (lanes 10-13) J558L nuclear extract $(10 \mu \mathrm{g})$ alone $(10)$, or with preimmune serum (11), or with anti-PU.l antiserum (12), or with anti-Pip antiserum (13). JB1, JB2, and JB3 indicate previously described protein-DNA complexes (Eisenbeis et al. 1993). (S) Supershifted complexes that appear upon addition of anti-PU.1 or antiPip antisera. (B) Western blot analysis of Pip in B lineage cells. (Lanes 1-3) Equimolar amounts of IVT Pip (1), ICSBP (2), and p48 (3). (Lanes 4-9) Total protein from $0.5 \times 10^{6}$ of the indicated cells. The blot was probed with anti-Pip antiserum. Protein size markers are indicated in kilodaltons (kDa). (C) Subcellular localization of Pip. NIH-3T3 cells were transiently transfected with an expression vector encoding an HAtagged Pip protein. Indirect immunoflourescence (left) and DAPI nuclear staining (center) were performed $48 \mathrm{hr}$. posttransfection. Nuclear localization of Pip was demonstrated by superpositioning of the two images (right). HAPip was detected with the 12CA5 anti-HA antibody.
(Fig. 1C, right panel). No specific signal was detected in cells transfected with the empty expression vector (data not shown).

\section{In conjunction with PU.1, Pip activates transcription, whereas ICSBP neither activates nor represses}

In previous work, we showed that PU.1 and Pip function as mutually dependent transcriptional activators in cotransfection assays with the B4-TKCAT reporter construct. This plasmid consists of a chloramphenicol acetyltransferase (CAT) gene located downstream of the thymidine kinase promoter and a tetramer of $\lambda B$ sites (Eisenbeis et al. 1993, 1995). In addition, we have shown that ICSBP, like Pip, interacts with PU.1 to form a ternary complex on the $\lambda B$ site of $E_{\lambda 2-4}$. Because ICSBP represses IFN-inducible transcription, we examined whether ICSBP also represses transcription in conjunction with PU.1.

Both Pip and ICSBP were epitope-tagged at their amino termini with the hemaglutinin nonapeptide $\left(\mathrm{HA}_{\text {; }}\right.$ Field et al. 1988), to create HAPip and HAICSBP, respectively. Gel mobility shift assays confirmed that both HAPip and HAICSBP formed a ternary complex with PU.1 and the $\lambda B$ site probe, similar to wild-type Pip and ICSBP (data not shown). We then cotransfected expression plasmids containing HAPip, HAICSBP, and PU.1, along with the
B4-TKCAT reporter into NIH-3T3 cells (Fig. 2A). Previously, we had reported that expression of PU.1 or Pip alone did not activate transcription. However, the current assays revealed that, although Pip alone did not activate, PU.1 stimulated transcription ninefold. We attribute PU.1-mediated activation to increased levels of protein expression in cells transfected with calcium phosphate (present study) instead of DEAE-dextran (Eisenbeis et al. 1995). Consistent with previous data, PU. 1 and Pip synergistically activated transcription $130-$ fold). When ICSBP was coexpressed with PU.1, however, no significant change in activation was detectable when compared with PU.1 alone. Gel mobility shift assays with the $\lambda B$ site probe detected equivalent levels of ternary complexes containing PU.1 and HAPip or PU.1 and HAICSBP in nuclear extracts from transfected cells (Fig. 2B). In addition, Western blotting showed that comparable levels of HAPip and HAICSBP were present in transfected cell lysates probed with a monoclonal antibody that recognizes the HA tag (Fig. 2C). These data revealed that, whereas the formation of a ternary complex involving PU.1, Pip, and DNA resulted in enhanced activation, the presence of ICSBP in a ternary complex with PU.1 neither stimulated nor repressed the latter's transcriptional activity. It should be noted that HAICSBP did repress $\alpha / \beta$-IFN-inducible transcription (see below). Thus, 

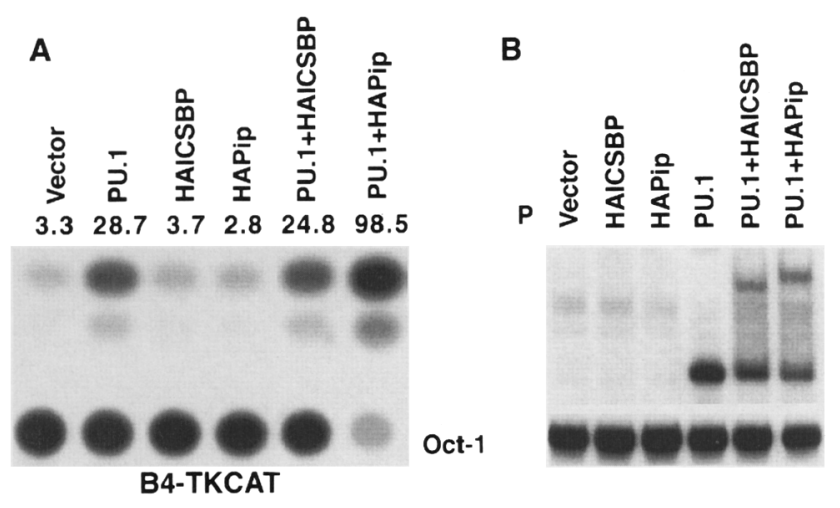

although Pip and ICSBP can equivalently interact with PU.1, only Pip promotes transcription.

\section{Pip contains an activation domain}

One potential explanation for the ability of Pip to enhance PU.1-mediated activation is that Pip, but not ICSBP, contains an activation domain. To address this possibilty, segments of the Pip protein were fused in frame to the DNA-binding domain of GAL4 (amino acids 1-147). The chimeric GAL4-Pip proteins were tested for their ability to activate transcription, in NIH-3T3 cells, of a reporter construct, 5XGAL4.E1BCAT, consisting of a CAT gene located downstream of an Elb minimal promoter and five GAL4-binding sites (Lillie and Green 1989|. Figure 3 demonstrates that pG4-Pipl-450, containing the full-length Pip protein, stimulated transcription (sixfold) when compared with pG4, which expresses the DNA-binding domain of GAL4. When the full-length Pip protein was subdivided into two segments, $1-150$ or 150-450, the amino-terminal portion containing the DNA-binding domain, pG4-Pip1-150, did not activate, but the carboxy-terminal fusion protein, pG4-Pip150450 , was 20 -fold more active than pG4. Transcriptional
Figure 2. Functional specificity of PU.1/ Pip and PU.1/ICSBP complexes. (A) Transient transfection analysis of the indicated expression constructs in NIH-3T3 cells. The reporter is the B4-TKCAT construct, containing a tetramer of $\lambda \mathrm{B}$ sites. CAT activity is expressed as percent conversion above each lane. $(B)$ Gel shift analysis of nuclear extracts $(10 \mu \mathrm{g})$ from NIH-3T3 cells transiently transfected with the indicated constructs. Assays were carried out with either a $\lambda B$ site probe or an octamer site probe, with the Oct-1 complex serving as a control. (P) Free probe. (C) Western blot analysis of NIH-3T3 cells transiently transfected with the indicated constructs. The blot was probed with the $12 \mathrm{CA} 5$ anti-HA antibody.

activation by GAL4-Pip fusion proteins was dependent on the presence of GAL4 DNA-binding sites (Fig. 3A, ElbCAT reporterj. The expression levels and DNA-binding properties of the fusion proteins were analyzed by gel mobility shift assays with whole-cell extracts and a probe containing five GAL4-binding sites (Fig. 3B). The fusion proteins were expressed at similar levels and bound DNA specifically, as determined by the ability of a 50 -fold molar excess of unlabeled probe to abolish the shifted complexes. Thus, Pip contains an activation domain that can function with a heterologous DNA-binding domain.

To determine whether the activation domain of Pip functions in the context of the ternary complex, we used an amino-terminal deletion mutant of PU.1, N100PU.1 (Shin and Koshland 1993), with Pip and the B4-TKCAT reporter. N100PU.1 is transcriptionally defective because of the deletion of an amino-terminal activation domain (Shin and Koshland 1993). However, N100PU.1 can both bind the $\lambda \mathrm{B}$ site and recruit Pip on the basis of gel mobility shift assays with transfected cell nuclear extracts (Fig. 4B). As seen in Figure 4A, N100PU.1 could not activate transcription on its own, but when both Pip and N100PU.1 are present, the two proteins produced a

Figure 3. Activation by GAL4-Pip chimeras. (A) Transient transfection analysis of the indicated expression constructs was performed by use of NIH-3T3 cells. (Left) Tranfections with the reporter ElbCAT; (right) transfections with the reporter $5 \times$ GAL4.E1bCAT, which contains five GAL4-binding sites. CAT activity is expressed as percent conversion above each lane. (B) Lysates of transfected cells were also assayed by gel mobility shifts with a probe containing five GAL4 sites, in the presence $(+)$ or absence $(-)$ of a 50 -fold molar excess of unlabeled competitor DNA.
A

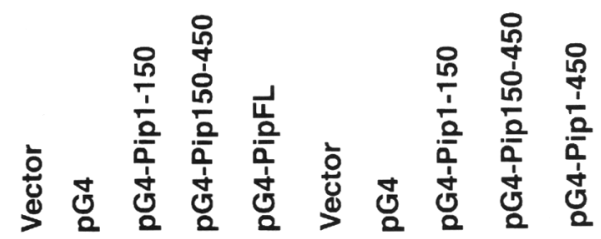

$\begin{array}{lllllllllll}0.4 & 0.6 & 0.8 & 0.6 & 0.9 & 1.2 & 0.9 & 0.9 & 21.1 & 5.9\end{array}$

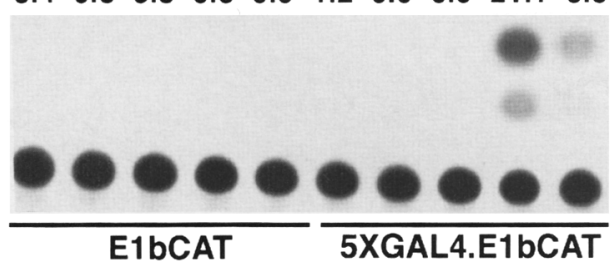

B

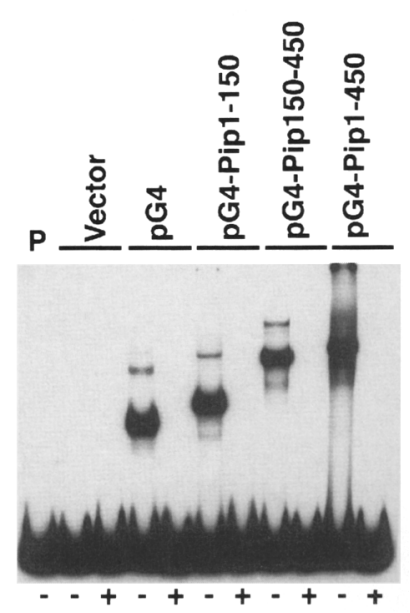




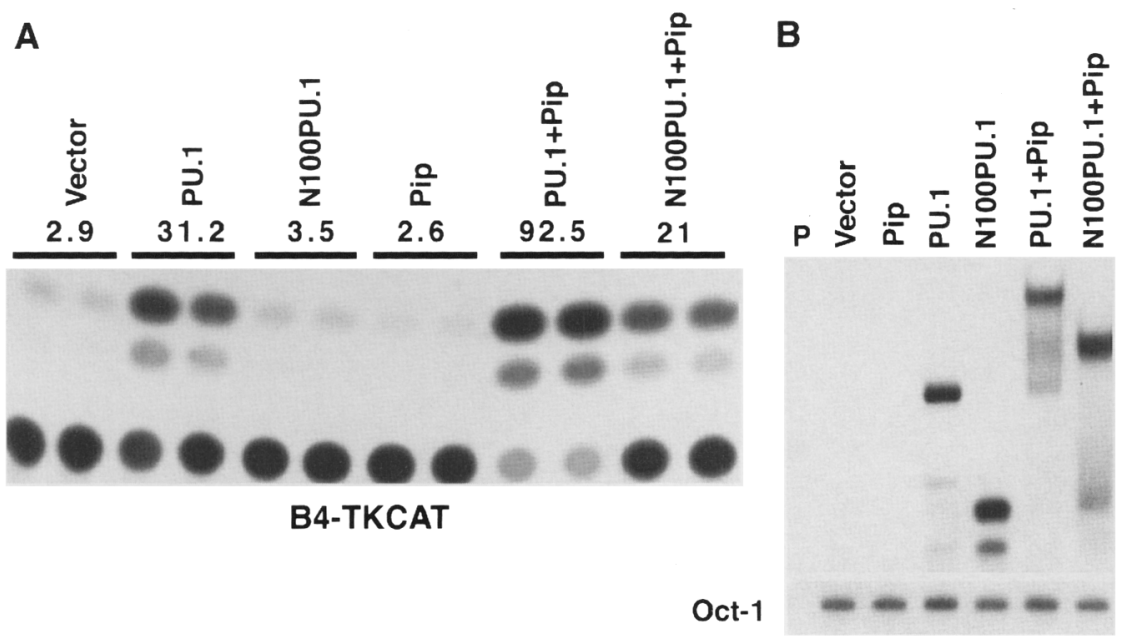

Figure 4. Activation by Pip in conjunction with a transcriptionally defective PU.1. $(A)$ Transient transfection analysis of the indicated constructs was conducted as in Fig. 2A. N100PU.1 is a mutant protein lacking the activation domain of PU.1 (Shin and Koshland 1993). The average CAT activity of duplicate transfections is expressed as percent conversion above each lane. $(B)$ Gel mobility shift analysis of nuclear extracts $(10$ $\mu \mathrm{g})$ from cells transfected with the indicated constructs was performed as in Fig. $2 \mathrm{~B}$. sevenfold activation of transcription, thus demonstrating that the transcriptionally defective N100PU.1 can recruit Pip to the $\lambda B$ site, thereby activating transcription. In light of the GAL-4-Pip fusion protein data, a likely explanation for these results is the presence of an activation domain within Pip /amino acids residues 150$450)$ that is recruited to the $\lambda \mathrm{B}$-containing reporter by PU.1. Therefore, we suggest that the functional difference between PU.1/Pip and PU.1/ICSBP complexes may be explained by the presence of an activation domain within Pip.

Pip represses $\alpha / \beta-I F N$-inducible transcription

Because Pip and ICSBP are closely related in sequence and ICSBP represses IFN-inducible transcription, we tested the effect of Pip on IFN-inducible transcription. Previously, we noted that the $\lambda \mathrm{B}$ element and the homologous element within $\mathrm{E}_{\kappa 3}$, are closely related to the ISRE consensus sequence (Eisenbeis et al. 1995). This suggested that the Ig composite elements could be recognized by the $\alpha / \beta$-IFN-inducible factors, IRF-1, IRF-2, and ISGF3. All three factors were found to specifically bind the $\lambda \mathrm{B}$ site (see below, data not shown). Figure $5 \mathrm{~A}$ shows that in NIH-3T3 cells, IRF-1, a positive regulator of IFN-induced transcription (Fujita et al. 1989; Harada et al. 1990|, strongly stimulated B4-TKCAT activity (9.5fold). The presence of the $\lambda \mathrm{B}$ sites was required for activation by IRF-1 because a similar reporter lacking these sites was not induced (data not shown). IRF-1-mediated activation was markedly decreased by coexpression of

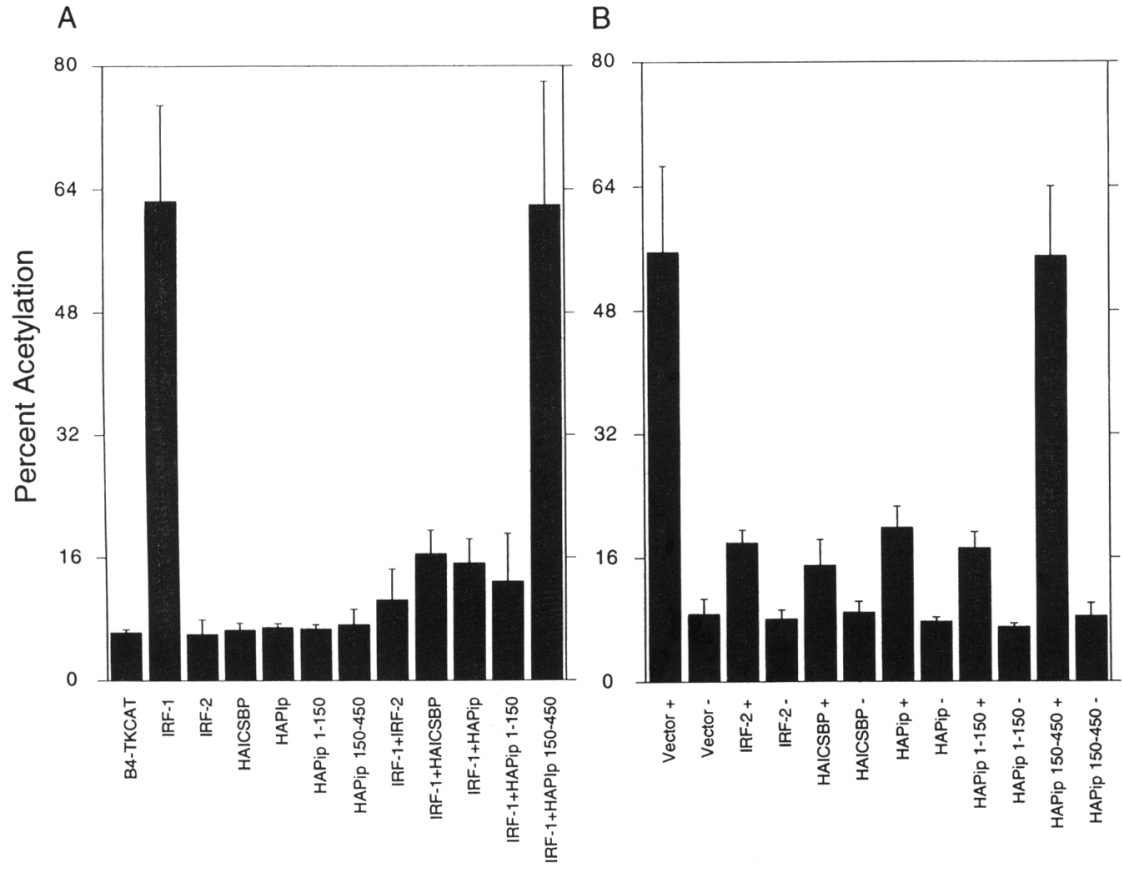

Figure 5. Pip represses IRF-1 - and $\alpha / \beta$-IFNmediated activation. (A) Transient transfection assays in NIH-3T3 cells were conducted with the indicated expression constructs and the B4-TKCAT reporter. $(B)$ NIH-3T3 cells were transiently transfected as above and incubated in the absence $(-)$ or presence $(+\mid$ of $\alpha / \beta$-IFN $(1000 \mathrm{U} / \mathrm{ml})$. Solid bars represent average percent acetylation of three independent transfections. Error bars denote standard deviation. 
HAPip, HAICSBP, or IRF-2. Moreover, the Pip mutant, Pip 1-150 /which consists of the minimal DNA-binding domain on the basis of our previous studies, Eisenbeis et al. 19951, also blocked IRF-1-mediated activation. In contrast, Pip 150-450 did not repress IRF-1-mediated activation. The expression of Pip 1-150 and 150-450 was confirmed with anti-HA Western analysis /data not shown). HAICSBP, HAPip, and HAPip 1-150 also inhibited the activation of B4-TKCAT in NIH-3T3 cells stimulated with $\alpha / \beta$-IFN (Fig. $5 B$ ). $\alpha / \beta$-IFN stimulation of NIH-3T3 cells resulted in inducible binding of IRF-1, IRF-2, and ISGF3 to the $\lambda B$ site (data not shown). These data demonstrate that Pip functions as a dichotomous regulator; it can block IRF-1 - and ISGF3-stimulated transcription in the absence of PU.1, or activate transcription in conjunction with PU.1. In addition, these experiments show that the DNA-binding domain of Pip is necessary and sufficient for repressing transcription. Possible mechanisms of Pip and ICSBP-mediated repression of transcription are addressed below (see Discussion).

The Pip segment amino acids 410-439 is required for autoinhibition of DNA-binding and is important for ternary complex formation with PU.1 and DNA

To delineate segments of Pip that are involved in interactions with PU.1, we progressively truncated Pip at its carboxyl terminus, and tested equimolar amounts of each mutant derivative for binding to a $\lambda \mathrm{B}$ site probe in a gel mobility shift assay (Fig. 6). The binding reactions were carried out in the absence or presence of equimolar PU.1 or PU.1 S148A, a PU.1 derivative that does not form a ternary complex with Pip, because it cannot be phosphorylated at serine 148 (Pongubala et al. 1993; Eisenbeis et al. 1995). As expected, full-length Pip, FL 1-450, did not bind DNA independently, but did form a ternary complex with PU.1 (Fig. 6, lanes 4,5). As noted, previous studies have shown that PU.1 S148A is unable to interact with Pip. In these assays, however, PU.1 S148A was able to weakly recruit FL $1-450$ to the $\lambda B$ site, albeit at a 9- to 10-fold lower level as compared with wild-type PU.1 (Fig. 6, cf. lanes 5 and 6). We attribute the detection of the PU.1 S148A/Pip complex to the lower levels of nonspecific DNA-binding competitor used in these gel mobility shift assays (see Materials and Methods). We have observed that binding of IRF domain factors to DNA is sensitive to increasing concentrations of poly $[\mathrm{d}(\mathrm{I}-\mathrm{C})]$. Thus, by use of these conditions, we were able to detect a weak interaction between PU.1, Pip, and DNA that is independent of the phosphorylation of PU.1 at serine 148. Deletion of the carboxy-terminal 11 amino acids of Pip, mutant 1-439, did not affect ternary complex formation. Removal of an additional 29 amino acids (1-410) however, greatly impaired ternary complex formation (12-fold reduction) and also enabled the independent binding of this Pip mutant to the $\lambda B$ site (Fig. 6, cf. lanes 4,5 , and 6 with lanes 10,11 , and 12). Continued deletion to amino acids 380 did not decrease ternary complex formation further, but did slightly increase PU.1-independent binding $(1.8$-fold $)$ in a reproducible

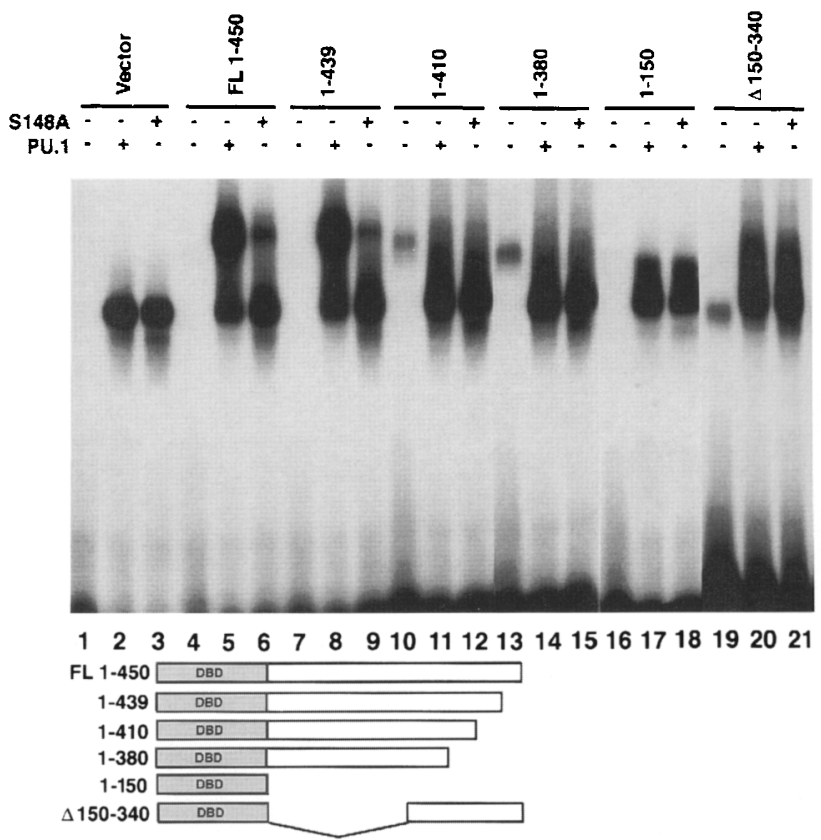

Figure 6. The Pip segment amino acids $410-439$ is important for autoinhibition of DNA binding and ternary complex formation with PU.1 and DNA. Gel mobility shift analysis of the indicated IVT Pip mutant derivatives in the absence $(-)$ or presence $(+)$ of PU.1 or PU.1 S148A (S148A) with the $\lambda B$ site as a probe. Equimolar amounts of the mutant proteins were used on the basis of PhoshorImager analysis of SDS-PAGE gels. Vector indicates an IVT reaction programmed with empty expression vector. The Pip derivatives are schematized below.

manner. Further deletions resulted in a progressive decrease of PU.1-independent binding activities for mutants, 1-340 and 1-300 (data not shown). Although at the levels of protein generated by in vitro expression, the Pip mutant 1-150 could not be seen to bind DNA in the absence of PU.1, it did form a weak ternary complex with PU.1 and $\lambda B$ DNA (Fig. 7, lanes 16-18). Finally, it should be noted that both PU.1-independent binding and formation of ternary complexes by the Pip mutants, $1-410,1-380$, and 1-150, were only detected with lower concentrations of poly[d(I-C)] (see Materials and Methods). These results demonstrate that a common segment of Pip (amino acids 410-439) is necessary for both autoinhibition of DNA binding and high-affinity ternary complex formation with PU.1.

Next, we constructed an internal-deletion Pip mutant, $\Delta 150-340$, to determine whether the carboxy-terminal region of Pip, including amino acids 410-439, was sufficient for both autoinhibition of DNA-binding and ternary complex formation. Pip $\Delta 150-340$ behaved comparably to the mutants, $1-410$ and $1-380$; it displayed PU.1-independent binding and formed weak ternary complexes (Fig. 6, lanes 19-21). Thus, the carboxy-terminal segment, amino acids 340-450, appears not to be sufficient for autoinhibition and high-affinity ternary complex formation in the context of $\Delta 150-340$. The internal segment, amino acids 150-340, may function as a 
A

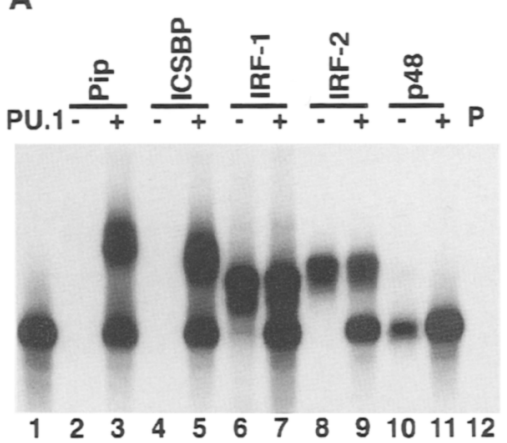

B

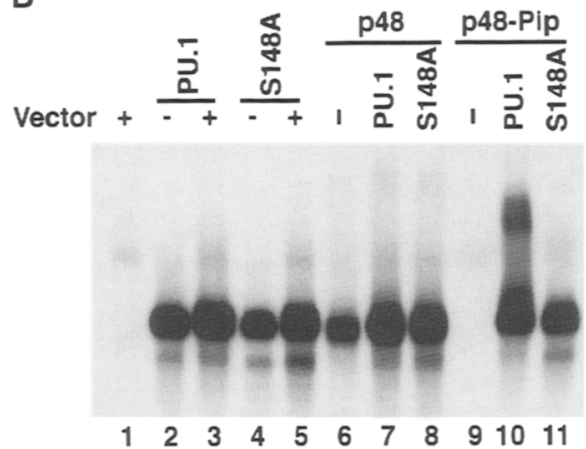

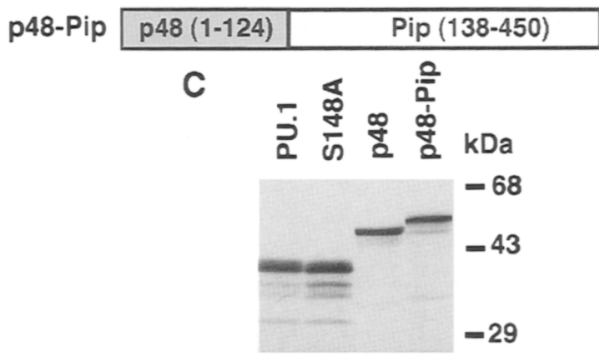

Figure 7. The Pip domain amino acids 138-450 confers autoinhibition and PU.1dependent binding activity to the DNAbinding domain of p48. $(A)$ Gel mobility shift analysis of the indicated IVT IRF proteins in the absence $(-)$ or presence $(+)$ of PU. 1 with a $\lambda B$ site probe. All proteins are present in equimolar amounts. $(B) \mathrm{Gel} \mathrm{mo-}$ bility shift analysis of the $\mathrm{p} 48$ or $\mathrm{p} 48-\mathrm{Pip}$ proteins in the absence $(-)$ or presence $(+)$ of PU.1 or PU.1 SI48A (S148A) with the $\lambda B$ site probe. Equimolar amounts of PU.1/ PU.1 S148A and p48/p48-Pip were used in the binding reactions. The $\mathrm{p} 48 / \mathrm{p} 48-\mathrm{Pip}$ proteins were present at twofold higher concentration than PU.1/PU.1 S148A. Vector $1+\mid$ indicates IVT reactions programmed with empty expression vector and used to normalize overall levels of reticulocyte lysate between reactions. $(C)$ SDS-PAGE analysis of $\left[{ }^{35} \mathrm{~S}\right]$-methionine labeled IVT proteins used for binding reactions. linker to allow proper positioning of the carboxy-terminal autoinhibitory domain. Alternatively, it may contain a region that is also required for the above functions.

\section{The Pip domain amino acids 138-450 confers autoinhibition and PU.1-dependent binding activity to the DNA-binding domain of $p 48$}

Next, we examined whether the ability to form a ternary complex with PU.1 and DNA was specific to Pip and ICSBP, or if this ability was more broadly shared by other members of the IRF family. Accordingly, equivalent moles of IVT IRF-1, IRF-2, p48, ICSBP, or Pip were assayed for DNA-binding to a $\lambda \mathrm{B}$-site probe, in the presence or absence of equimolar IVT PU.1 (Fig. 7A). Of the IRFs tested, only ICSBP and Pip displayed PU.1-dependent binding characteristics. Although IRF-1, IRF-2, and p48 showed significant binding to the $\lambda B$ site, they did not form ternary complexes with PU.1.

In an attempt to confer PU.1-dependent binding activity to a related IRF, we constructed a p48-Pip chimeric protein containing the DNA-binding domain of murine p48 (amino acids 1-124; Veals et al. 1993; D. Levy, pers. comm.) fused in frame to amino acid residues $138-450$ of Pip (Fig. 7B, bottom). We chose p48 for construction of the fusion protein on the basis of its lower relative affinity for the $\lambda B$ site and its carboxy-terminal sequence similarity to Pip and ICSBP. Figure 7B shows a gel mobility shift assay with the in vitro translated proteins displayed in Figure $7 \mathrm{C}$. This assay revealed that, whereas $\mathrm{p} 48$ could independently bind $\lambda \mathrm{B}$ DNA, the p48-Pip chimeric protein could not (Fig. 7B, cf. lanes 6 and 9). Furthermore, p48-Pip, similar to Pip and ICSBP, interacted with PU.1 and $\lambda B$ DNA to form a ternary complex. The use of the PU.1 derivative, PU.1 S148A, demonstrated that the for- mation of the PU.1/p48-Pip complex was dependent on the phosphorylation of serine residue 148 (Fig. 7B, lanes $10,11)$. This last result is in contrast to the ability of Pip to interact weakly with PU.1 S148A (Fig. 6, lane 6) and may reflect specific interactions between the DNA-binding domain of Pip and PU.1 that are not conserved between PU.1 and the DNA-binding domain of $\mathrm{p} 48$. The formation of the PU.1/p48-Pip complex was also dependent on the integrity of the $\lambda B$ site because a mutation in this element (GTGAAACCAA to GTCGTACCAA), previously shown to abolish Pip binding, also blocked p48Pip binding (data not shown; Eisenbeis et al. 1993). These experiments demonstrate that Pip amino acids 138-450 represent a functional domain that is both necessary and sufficient to confer autoinhibition and PU.1dependent DNA-binding.

\section{Discussion}

Pip and ICSBP differ in their PU.1-associated function

Our results show that the PU.1/Pip complex functions to synergistically activate transcription. In contrast, the level of PU.1-mediated activation was neither enhanced nor inhibited by ICSBP. Thus, an implication of these results is that the activity of the $\kappa$ and $\lambda$ enhancers containing these composite elements may be modulated by the relative levels of Pip and ICSBP. For example, excess levels of ICSBP may displace/block Pip from the PU.1containing $E_{\lambda 2-4}, E_{\lambda 3-1}$, and $E_{\kappa 3}$, complexes, thus inhibiting transcriptional activity. Therefore, it will be of considerable interest to determine how the relative levels of Pip and ICSBP regulate the expression of Ig light-chain genes during B-cell development and activation.

Although our data revealed that PU.1 alone could ac- 
tivate, it is important to note that we were assaying a synthetic tetramer of $\lambda B$ sites and, therefore, it is conceivable that in vivo the displacement of Pip by ICSBP may more significantly diminish activation of the native enhancer. For example, our earlier transfection studies demonstrated that under conditions of lower levels of protein expression, PU.1 and Pip are mutually dependent activators of this same element (Eisenbeis et al. 1995).

The results of the PU.1/ICSBP cotransfections are consistent with our previous postulate (Eisenbeis et al. 1995) that an inhibition of enhancer activity by ICSBP may favor both transcriptional activation and recombination of the $\kappa$ locus over the $\lambda$ locus because of the latter's complete reliance on PU.1/Pip-dependent enhancer elements for activation. Recently, our suggestion that ICSBP may antagonize PU.1/Pip activity at the $\mathrm{E}_{\kappa}$, has been extended to explain the loss of cell type- and stagespecific regulation of $\kappa$ light-chain gene recombination observed when the PU.1 site within this element is mutated (Hiramatsu et al. 1995). Again, our current results with PU.1 and ICSBP support this hypothesis. A prediction of this model is that ICSBP mutant mice will possess a larger percentage of $\lambda$-expressing $B$ cells as well as aberrant control of light-chain gene recombination, perhaps resulting in precocious light-chain expression.

\section{Pip contains an activation domain}

The observation that Pip and PU.1 synergistically activated transcription led us to consider the possibility that Pip contains an activation domain. When fused to a heterologous DNA-binding domain, full-length Pip and Pip amino acids $150-450$ activated transcription. Furthermore, wild-type Pip activated transcription in the presence of a transcriptionally inactive PU.1. Taken together, these experiments demonstrate that Pip possesses an activation domain. Similar fusions of ICSBP with GAL4 failed to reveal the presence of an activation domain (Sharf et al. 1993). Two regions within the amino acids 150-450 segment of Pip may serve as activation domains: a proline-rich segment (amino acids 151-237) and a carboxy-terminal region (amino acids 354-419) containing $15 \%$ glutamine residues.

\section{Pip functions as a dichotomous regulator}

Our results show that the $\lambda B$ element of $E_{\lambda 2-4}$ is a functional ISRE and that Pip negatively regulates IRF-1- or $\alpha / \beta$-IFN-stimulated activation of this element. Moreover, HAPip and HAICSBP blocked the IRF-1-mediated activation of a reporter containing the hamster ISG-54 K promoter, which possesses two adjacent ISREs (data not shown; Bluyssen et al. 1994). In addition, during the completion of this manuscript, it was reported that the human homologue of Pip blocked $\alpha / \beta$-IFN-activated transcription (Yamagata et al. 1996). Therefore, Pip acts as a dichotomous regulator (Roberts and Green 1995), it activates transcription upon forming a ternary complex with PU.1, but represses transcription on its own by inhibiting IRF-1 or ISGF3.
The mechanism by which Pip blocks IRF-1- and ISGF3-mediated activation may involve direct competition for DNA binding. In support of this hypothesis, we have shown that the Pip mutant containing the aminoterminal DNA-binding domain, Pip 1-150, blocked $\alpha / \beta$ IFN-mediated transcription. Similar results have been reported for a mutant derivative of ICSBP, containing the minimal DNA-binding domain (Nelson et al. 1993). Furthermore, full-length ICSBP and its DNA-binding domain derivative have been shown to block the antiviral transcriptional response when stably expressed in monocytic cells (Thornton et al. 1996). Although full-length Pip protein and the mutant $1-150$ produced by in vitro translation did not show detectable binding to the $\lambda \mathrm{B}$ element (Fig. 6), they can be seen to bind the $\lambda \mathrm{B}$ site probe in extracts of transiently transfected NIH-3T3 cells with low levels of poly[d(I-C)] (data not shown). We attribute this difference to the higher levels of protein expression achieved by transient transfection. Western analysis of extracts from transfected cells demonstrated that full-length Pip and the 1-150 mutant were expressed at significantly higher levels than achieved by in vitro translation (data not shown). Similarly, independent binding of Pip to DNA has been reported recently by use of high concentrations of recombinant protein expressed with baculovirus (Matsuyama et al. 1995) or GST systems (Yamagata et al. 1996). Thus, it is conceivable that an excess of the lower affinity Pip protein may exclude IRF-1 or ISGF3 from binding to an ISRE, thereby inhibiting $\alpha / \beta$-IFN-mediated activation.

Alternatively, Pip may inhibit transcription by direct protein-protein interactions with IRF-1 or ISGF3. ICSBP forms complexes with IRF-1 and IRF-2 and these interactions have been hypothesized to contribute to ICSBP's repression of transcriptional activation by these factors (Bovolenta et al. 1994). Although we were able to reproduce the formation of complexes between ICSBP and IRF-1 or IRF-2 in gel mobility shift assays, we did not detect comparable complexes between Pip and IRF-1 or IRF-2 under the conditions tested (data not shown).

It is important to note that Pip does not autonomously stimulate transcription, even though it contains both an activation domain and can bind DNA when present at sufficiently high protein concentrations. One possible explanation is that, whereas the low affinity interaction of Pip with DNA effectively inhibits the binding of IRF1 , it may nevertheless be of insufficient duration and/or stability to allow Pip to promote activation by efficiently interacting with the basal transcriptional machinery. Thus, PU. 1 may convert Pip into an activator by more stably associating Pip to an enhancer. Consistent with this hypothesis is our demonstration that the fusion of Pip to a high affinity DNA-binding domain (GAL4) generates a transcriptional activator (Fig. 3A).

What might be the biological significance of the ability of Pip to both activate and repress transcription? In this regard, it is interesting to note that Pip is a cell-type restricted repressor of $\alpha / \beta$-IFN-inducible transcription. Therefore, Pip may function as a buffering agent in lymphoid cells exposed to $\alpha / \beta$-IFN, by attenuating expres- 
sion of IFN-inducible genes. During an immune response, B cells are exposed to antigen and cytokine stimuli. The recognition of antigen by a B-cell receptor results in proliferation and differentiation (DeFranco 1993). During such a response, B cells may also encounter $\alpha / \beta$-IFNs, with a major function of these cytokines being the establishment of an antiviral state, which renders cells nonproliferative (Friedman et al. 1986). Pip expression is induced in B cells by bacterial lipopolysaccharide as well as the antigen-mimetic stimulus, antiIgM (Matsuyama et al. 1995). Perhaps, upon exposure to antigen, an increase in the expression of Pip serves to inhibit the antiproliferative effects of $\alpha / \beta$-IFNs, thereby facilitating lymphocyte proliferation. In addition, the ability of PU.1 and Pip to function as synergistic transcriptional activators in B lymphocytes may allow antigen-induced increases in Pip expression to stimulate the activity of Ig light-chain genes as well as other genes containing the composite elements. Therefore, during an immune response, Pip as a repressor may lessen the antiproliferative effects of $\alpha / \beta$-IFN, whereas in concert with PU.1, Pip as an activator may up-regulate B-cellspecific gene expression.

It should be noted that, whereas the $\lambda \mathrm{B}$ composite element can function as an ISRE, the converse appears not to be the case. The following ISREs; ISG15, MHC 1, and ISG-54 K (Schindler and Darnell 1995) do not support PU.1/Pip ternary complex formation (data not shown). Thus, although activation via an ISRE can be inhibited by Pip, an ISRE is unlikely to be activated by the PU.1/ Pip complex.

\section{Structural basis for PU.1-dependent DNA-binding of Pip}

Our results show that Pip amino acids 138-450 contain the structural determinants for both autoinhibition of DNA-binding and specific association with PU.1, and thus function as a regulatory domain that is distinct from the DNA-binding domain. Within the regulatory domain, deletional analysis revealed a segment of Pip, amino acids $410-439$, which is important for both autoinhibition and ternary complex formation, suggesting that the same structural determinant may be responsible for both these activities. The possibility remains, however, that these functions may be structurally separable and resolution of this issue awaits finer mutational analysis. In addition, the correlation between loss of autoinhibition and diminished ternary complex formation observed with the carboxy-terminal Pip mutants, suggests that an interaction of the autoinhibitory segment of Pip with PU.1 may alleviate intramolecular inhibition of DNA-binding. So far, attempts to demonstrate a direct interaction between PU.1 and Pip in the absence of DNA have been unsuccessful. One possible explanation is that DNA binding is required to produce the activated conformation of a domain within one or both proteins, which is essential for protein-protein interaction. This scenario is appealing because it postulates that the assembly of PU.1/Pip complexes is critically dependent on both protein-protein and protein-DNA interactions, thus providing an additional level of template-directed specificity (McKnight 1996). Such a model of regulated binding has been proposed in a recent study involving the ets-1 protein, which contains two domains that inhibit DNA-binding (Petersen et al. 1995; Jonsen et al. 1996).

A carboxy-terminal segment of p48 (amino acids 204 393), when fused to the DNA-binding domain of IRF-1 (amino acids 1-250), can mediate the formation of a ternary complex with STAT1 and STAT2 / Veals et al. 1993). This region of $\mathrm{p} 48$ has been posited to function as a protein-protein interaction domain with these STATs (Veals et al. 1993). Within a 124-amino acids carboxyterminal region of Pip (amino acids 299-422), strong sequence homology is apparent with both ICSBP /amino acids $260-383,48 \%$ identity) and p48 (amino acids 258$381,33 \%$ identity). In light of this homology, it is important to consider that our assays and those of others have failed to reveal the formation of ternary complexes containing PU.1/p48, STAT/Pip, or STAT/ICSBP on $\lambda \mathrm{B}$ or ISRE probes (Fig. 7A,B; D. Levy, pers. comm.; Bovolenta et al. 1994). Thus, Pip, ICSBP, and p48 contain homologous carboxy-terminal regions that may mediate highly selective protein-protein interactions, resulting in the formation of distinct ternary complexes. Consistent with this hypothesis, deletional analysis of p48 revealed a carboxy-terminal region, amino acids 378-393, required for efficient ternary complex formation with STATs; the deletion of an additional 10 carboxy-terminal residues of p48, to amino acid 367, completely blocked ISGF3 formation (Veals et al. 1993). Regions of Pip (amino acids 399-4613) and p48 (amino acids 364378) encompassing these deletion termini, and a homologous region of ICSBP (amino acids 361-375), are predicted to form similar $\alpha$-helical secondary structures (Fig. 8B; Veals et al. 1993; Garnier et al. 1978). On the basis of these considerations, we postulate that this $\mathrm{pu}-$ tative $\alpha$-helical region may play a key role in both ternary complex formation and in the case of Pip and ICSBP, autoinhibition of DNA binding.

\section{Model of PU.1/Pip ternary complex formation}

On the basis of the above observations, we propose the following hypothetical model of PU.1/Pip interaction: The carboxy-terminal segment of Pip containing the putative $\alpha$-helix, amino acids $399-413$, functions as an inhibitory domain (ID); by interacting with the amino-terminal DNA-binding domain of Pip, it causes autoinhibition of DNA binding (Fig. 8A, left). Interaction of the inhibitory domain of Pip with the region of PU.1 containing phosphoserine 148 disrupts this autoinhibition, thereby allowing the DNA-binding domain of Pip to contact DNA with higher affinity (Fig. 8A, right). An analogous phosphoserine-dependent ternary complex, between the transcription factor, CREB, and the coactivator, CBP, has been shown to involve protein-protein interactions directly mediated by a phosphoserine residue (Parker et al. 1996). It should be noted that an addi- 
Figure 8. Hypothetical model of PU.1/Pip ternary complex formation. $(A)$ Autoinhibition of the DNA binding activity of Pip is indicated by an interaction between the amino-terminal DNA-binding domain (DBD) and a carboxy terminal inhibitory domain (ID). This inhibition is alleviated by an interaction between the ID of Pip and a putative PEST region of PU.1 containing phosphoserine $148(\mathrm{P})$. Additional contact may occur between the respective DBDs of PU. 1 and Pip. The relative locations of the activation domains (AD) of Pip and PU.1 are also indicated. Boxed sequences denote the Pip and PU.1 footprints as determined by methylation interference assays (Pongubala et al. 1992; Eisenbeis et al. 1993). (B) Helical wheel analysis of regions of Pip (amino acids 399-413), ICSBP (amino acids 361-375), and p48 (amino acids 364-378) encoding putative $\alpha$-helices. The incremental angle is $100^{\circ} \mathrm{C}$ and residues that are conserved between Pip and ICSBP are underlined. Residues in p48 that are conserved with both Pip and ICSBP are also underlined. The position of the carboxy-terminal deletion mutation of Pip that results in loss of both autoinhibition of DNA binding and efficient interaction with PU. 1 is indicated (a). Carboxy-terminal deletion mutations of p48 that result in abolishment (b) or reduction (c) of ISGF3 formation are also designated (Veals et al. 1993).

tional interaction may occur between the DNA-binding domain of Pip and PU.1, possibly with the latter's Ets domain contributing to the ability of Pip to bind DNA. In support of this last assertion, we sight the PU.1-mediated recruitment of Pip 1-150 into a ternary complex, the juxtapositioning of the PU.1 and Pip footprints as determined by methylation interference assays (Fig. 8A; Pongubala et al. 1992; Eisenbeis et al. 1993), and the inability of PU.1 to recruit Pip to a $\lambda B$ element that has $2 \mathrm{bp}$ inserted between the PU.1 and Pip binding sites /C. Eisenbeis, H. Singh, and U. Storb, unpubl.). As depicted, the simplest explanation for these postulated interactions is that they are of a direct nature; however, whether they are indeed direct, or alternatively occur via allosteric mechanisms, will be the focus of future investigation.

\section{Materials and methods}

\section{Plasmids}

HA-tagged Pip and ICSBP constructs were prepared by polymerase chain reaction (PCR) amplification of relevant cDNA segments with Pfu polymerase (Stratagene), digestion of these cDNAs with Not 1 and $X b a I$ and cloning into pcDNA3-HA. pcDNA3-HA is a derivitive of pcDNA3-NEO (Invitrogen) containing an HA nonapeptide coding sequence immediately downstream of a consensus eukaryotic initiation codon. pcDNA3-HA was created by insertion of the synthetic oligonucleotides

GCGGCCGCCGGCATAGTCAGGCACGTCATAAGGATAGGCCATGGCGGC CGGCCGTATCAGTCCGTGCAGTATTCCTATCCGGTACCGCCGTTCGA

into a HindIII-NotI-digested pcDNA3-NEO. Murine p48 cDNA was the kind gift of D. Levy (New York University, NY) and a full-length p48 construct containing a consensus translation initiation site was constructed by PCR. The resulting cDNA was digested with $K p n I$ and $X b a I$ and cloned into pcDNA3NEO. The GAL4-Pip chimeras were created by PCR, and the resulting cDNAs were digested with $B a m H I$ and $X b a I$ and cloned into pcDNA3-GAL4 (pG4, the kind gift of E. Morrisey and M. Parmacek, University of Chicago, Chicago, IL). pG4 is a derivative of pcDNA3-NEO containing the GAL4 DNA-binding domain (amino acids 1-147). The murine p48-Pip chimeric construct was created by use of sequence-overlap extension PCR (Ho et al. 1989) and the resulting cDNAs were digested with $K p n I$ and $X b a I$ and cloned into pcDNA3-NEO. The structures of all constructs described were confirmed by dideoxy sequencing. Other constructs used in this study have been described previously: N100PU.1 (Shin and Koshland 1993); pACT-IRF-1, pACT-IRF-2, and pACT-C (Harada et al. 1990); Pip/CMV and PU.1/CMV (Eisenbeis et al. 1995).

\section{In vitro translation}

In vitro translations were performed with $1 \mu \mathrm{g}$ of the indicated plasmid and a TNT coupled transcription/translation kit (Promega) as per the manufacturer's instructions. $\left[{ }^{35} \mathrm{~S}\right]$ methionine labeled IVT proteins were resolved in a $10 \%$ or $12.5 \%$ SDS-polyacrylamide gel and quantitated by use of the PhosphorImager system (Molecular Dynamics).

\section{Gel mobility shift assays}

Nuclear extracts were prepared as described previously (Eisenbeis et al. 1993). A synthetic oligonucleotide containing the murine $\lambda B$ sequence, 5 '-CTAGCGAGAAATAAAAGGAAGTGAAACCAAGT- $3^{\prime}$ was annealed to the complimentary oligo- 
nucleotide and end labeled with $\left[{ }^{32} \mathrm{P}\right] \mathrm{dCTP}$ by use of the Klenow fragment. DNA binding reactions contained $2.5 \times 10^{5} \mathrm{cpm}$ of probe and $10 \mu$.g of nuclear extract or $1-2 \times 10^{-14}$ moles of IVT protein in a final volume of $20 \mu \mathrm{l}$. The two different binding reaction conditions used have been described previously (Eisenbeis et al. 1993, $4.0 \mu \mathrm{g}$ of poly[d(I-C)] per reaction; Figs. 1A, 2C, and 4B; Matsuyama et al. 1995, $0.5 \mu \mathrm{g}$ of poly [d(I-C)] per reaction, Figs. 6, 7A, 7B|. Binding reactions were incubated for 20 min at room temperature and electrophoresed on a $1 \times$ TGE (Fig. $1 \mathrm{~A}, 2 \mathrm{C}$, and $4 \mathrm{~B}$ ) or a $0.25 \times$ TBE (Fig. $6,7 \mathrm{~A}$, and $7 \mathrm{~B}$ ) $5 \%$ native polyacrylamide gel at $300 \mathrm{~V}$ for $2 \mathrm{hr}$. Antibody supershift assays were performed by incubating complete gel shift reactions for $20 \mathrm{~min}$ followed by addition of $2 \mu \mathrm{l}$ of either anti-Pip antiserum, anti-PU.1 antisenum, or rabbit preimmune serum. Rabbit antiPU.1 and anti-Pip antisera were raised against purified GSTfusion proteins containing full-length PU.1 or full-length Pip. Binding of GAL4-Pip chimeras was assayed as described previously by Gashler et al. (1993). Quantitation of gel mobility shift assays was performed by use of the PhophorImager system and represent the average of at least three independent experiments.

\section{Western analysis}

Total cellular proteins from $0.5 \times 10^{6}$ cells were resolved in a $10 \%$ SDS-polyacrylamide gel and transferred to an Immobilon-P membrane (Millipore). The blots were incubated with a $1 \mu \mathrm{g} / \mathrm{ml}$ dilution of murine 12CA5 anti-HA monoclonal antibody (Boehringer Mannheim) or a 1:1000 dilution of rabbit anti-Pip antiserum. Immunoreactive proteins were detected with the enhanced chemiluminescence (ECL) reagent system (Amersham).

\section{Indirect immunofluorescence analysis}

NIH-3T3 cells were plated at a density of $1 \times 10^{6}$ cells per 10 $\mathrm{cm}$ diameter dish $24 \mathrm{hr}$ before transfection. Cells were transfected as described below, wth either pcDNA3-HAPip or pcDNA3-HA as a control. At $48 \mathrm{hr}$ post-transfection, cells were prepared for visualization essentially as described by Beg et al. (1992) by use of a murine 12CA5 anti-HA primary antibody $(20$ $\mu \mathrm{g} / \mathrm{ml}$ ), a rhodamine-conjugated goat antimouse $\mathrm{IgG}$ secondary antibody (1:20, Boehringer Mannheim) and DAPI (Boehringer Mannheim). Slides contained fluorescent mounting media (Kirkegaard \& Perry Laboratories) and were viewed with a fluorescence light microscope (Zeiss).

\section{Transient transfection analysis}

NIH-3T3 cells were cultured in Dulbecco's modified Eagle's medium with $10 \%$ fetal bovine serum (Hyclone) and penicillinstreptomycin-glutamine and transiently transfected by standard calcium phosphate-mediated precipitation. In experiments involving $\alpha / \beta$-IFN stimulation, NIH-3T3 cells were incubated with DNA precipitate for $18 \mathrm{hr}$, the media was then changed and the cells incubated in the presence or absence of $1000 \mathrm{U} / \mathrm{ml}$ of murine $\alpha / \beta$-IFN (Lee Biomolecular) for $10 \mathrm{hr}$, whereupon the media was changed and the cells harvested after an additional $20 \mathrm{hr}$ incubation. For transfections involving GAL4-Pip chimeric proteins, $20 \mu \mathrm{g}$ of the indicated expression vector and $2 \mu \mathrm{g}$ of the reporter (either GAL4E1bCAT or E1BCAT, Lillie and Green 1989) were used. Each precipitate also contained $1.5 \mu \mathrm{g}$ of a $\beta$-actin-driven $\beta$-galactosidase reporter $(\beta$-ACT- $\beta$-GAL) as an internal reference. All other transient transfections used a total of $20 \mu \mathrm{g}$ of DNA; $2.5 \mu \mathrm{g}$ of the B4-TKCAT reporter construct (Eisenbeis et al. 1993), $2.5 \mu \mathrm{g}$ of the indicated expression vector(s), and $1.5 \mu \mathrm{g}$ of a $\beta$-galactosidase containing reference plas- mid (MSV- $\beta$-GAL or $\beta$-ACT- $\beta$-GAL), with the balance made up by an appropriate empty expression vector. After $48 \mathrm{hr}$ at $37^{\circ} \mathrm{C}$, cells were trypsinized and lysed by three cycles of freeze-thawing. CAT assays were performed as described in Gorman et al. (1982), after normalization for $\beta$-galactosidase activity as determined spectrophotometrically (Rosenthal 1987). CAT assays were quantitated by PhosphorImager; the results shown are representative of at least three independent transfections. Variation of data points between experiments was $<20 \%$.

\section{Acknowledgments}

We are extremely grateful to David Levy (New York University) for reagents, advice and communicating results and plasmids before publication. We also thank Marian Koshland (University of California, Berkeley) and Keiko Ozato (National Institutes of Health) for sharing reagents, Nancy Zeleznik-Le for technical advice, Gail Hubbard for help in the preparation of this manuscript and Terry Martin and Nipam Patel for their assistance with indirect immunoflourescence. We thank Alita Miller, Andrew Wagner, Michael Palopoli, and Pratik Shah for their critical review of the manuscript. In addition, we thank Jenny Yu and Sheila Gerety for generating the anti-PU.1 antiserum and Arunangsu Dey for demonstrating that the $\lambda B$ element functions as an ISRE. This work was supported by the Howard Hughes Medical Institute (E.K. and H.S.), American Cancer Society grant IM-623 (U.S.) and NIH training grants HD07009 (A.L.B.); GMO7281 and FM07183 (C.F.E.).

The publication costs of this article were defrayed in part by payment of page charges. This article must therefore be hereby marked "advertisement" in accordance with 18 USC section 1734 solely to indicate this fact.

\section{References}

Beg, A.A., S.M. Ruben, R.I. Scheinman, S. Haskill, C.A. Rosen, and A.S. Baldwin Jr. 1992. IкB interacts with the nuclear localization sequences of the subunits of NF- $\mathrm{B}$ : A mechanism for cytoplasmic retention. Genes \& Dev. 6: 189919213.

Bender, A. and G.F. Sprague. 1987. MAT $\alpha 1$ protein, a yeast transcription activator, binds synergistically with a second protein to a set of cell-type-specific genes. Cell 50: 681-691.

Bluyssen, A., R. Vlietstra, A. Van Der Made, and J. Trapman. 1994. The interferon-stimulated gene $54 \mathrm{~K}$ promoter contains two adjacent functional interferon-stimulated response elements of different strength, which act synergistically for maximal interferon- $\alpha$ inducibility. Eur. I. Biochem. 220: 395-402.

Bovolenta, C., P. Driggers, M. Marks, J. Medin, A. Politis, S. Vogel, D. Levy, K. Sakaguchi, E. Appella, J. Coligan, and K. Ozato. 1994. Molecular interactions between interferon consensus sequence binding protein and members of the interferon regulatory factor family. Proc. Natl. Acad. Sci. 91: 5046-5050.

Dalton, S. and R. Treisman. 1992. Characterization of SAP-1, a protein recruited by serum response factor to the $c$-fos serum response element. Cell 68: 597-612.

Defranco, A. 1993. B lymphocyte activation, In Fundamental immunology (ed. W.E. Paul), pp. 505-529. Raven Press Ltd., New York, NY.

Driggers, P., D. Ennist, S. Gleason, W.-H. Mak, M. Marks, B.-Z. Levi, J. Flanagan, E. Appella, and K. Ozato. 1990. An interferon $\gamma$-regulated protein that binds the interferon-inducible enhancer element of major histocompatibility complex class 
I genes. Proc. Natl. Acad. Sci. 87:3743-3747.

Eisenbeis, C., H. Singh, and U. Storb. 1993. PU.1 is a component of a multi-protein complex which binds an essential site in the murine immunoglobulin $\lambda 2-4$ enhancer. Mol. Cell. Biol. 13: 6452-6461.

- 1995. Pip, a novel IRF family member, is a lymphoidspecific, PU.1-dependent transcriptional activator. Genes \& Dev. 9: 1377-1387.

Field, J., J. Nikawa, D. Broek, B. MacDonald, L. Rodgers, I.A. Wilson, R.A. Lerner, and M. Wigler. 1988. Purification of a RAS-responsive adenyl cyclase complex from Saccharomyces cerevisiae by use of an epitope addition method. Mol. Cell. Biol. 8: 2159-2165.

Friedman, R., T. Merigan, and T. Sreevalsan. 1986. Interferons as cell growth inhibitors and antitumor factors. Alan $\mathbf{R}$. Liss, New York, NY.

Fujita, T., Y. Kimura, M. Miyamoto, L. Barsoumian, and T. Taniguchi. 1989. Induction of endogenous IFN- $\alpha$ and IFN- $\beta$ genes by a regulatory transcription factor, IRF-1. Nature 337: $270-272$

Galson, D., J. Hensold, T. Bishop, M. Schalling, A. D'Andrea, C. Jones, P. Auron, and D. Housman. 1993. Mouse $\beta$-globin DNA-binding protein B1 is identical to a proto-oncogene, the transcription factor Spi-1/PU.1, and is restricted in expression to hematopoietic cells and testis. Mol. Cell. Biol. 13: 2929-2941.

Garnier, J., D.J. Osguthorpe, and B. Robson. 1978. Analysis of the accuracy and implications of simple methods for predicting the secondary structure of globular proteins. J. Mol. Biol. 120: 97-120.

Gashler, A., S. Swaminathan, and V. Sukhatme. 1993. A novel repression module, an extensive activation domain, and a bipartite nuclear localization signal defined in the immediate-early transcription factor Egr-1. Mol. Cell. Biol. 13: 4556-4571.

Gorman, C.M., L.F. Moffat, and B.H. Howard. 1982. Recombinant genomes which express chloramphenicol acetyltransferase in mammalian cells. Mol. Cell. Biol. 2: 1044-1051.

Harada, H., T. Fujita, M. Miyamoto, Y. Kimura, M. Maruyama, A. Furia, T. Miyata, and T. Taniguchi. 1989. Structurally similar but functionally distinct factors, IRF-1 and IRF-2, bind to the same regulatory elements of IFN- $\beta$ and IFN-inducible genes. Cell 58: 729-739.

Harada, H., K. Willison, J. Sakakibara, M. Miyamoto, T. Fujita, and T. Taniguchi. 1990. Absence of the type 1 IFN system in EC cells: Transcriptional activator (IRF-1) and repressor (IRF-2) genes are developmentally regulated. Cell 63: 303312.

Hiramatsu, R., K. Akagi, M. Matsuoka, K. Sakumi, H. Nakamura, L. Kingsbury, C. David, R. Hardy, K. Yamamura, and H. Sakano. 1995. The 3' enhancer region determines the B/T specificity and pro-B/pre-B specificity of immunoglobulin $\mathrm{V}_{\mathrm{k}}-\mathrm{J}_{\mathrm{k}}$ joining. Cell 83: $1113-1123$.

Ho, S., H. Hunt, R. Horton, J. Pullen, and L. Pease. 1989. Sitedirected mutagenesis by overlap extension using the polymerase chain reaction. Gene 77: 51-59.

Jonsen, M., J. Petersen, Q.-P. Xu, and B. Graves. 1996. Characterization of the cooperative function of inhibitory sequences in ets-1. Mol. Cell. Biol. 16: 2065-2073.

Judde, J. and E. Max. 1992. Characterization of the human immunoglobulin kappa gene 3' enhancer: Functional importance of three motifs that demonstrate B-cell-specific in vivo footprints. Mol. Cell. Biol. 12: 5206-5216.

Katan, M., A. Haigh, C.P. Verrijer, P.C. van der Vliet, and P. O'Hare. 1990. Characterization of a cellular factor which interacts functionally with Oct-1 in the assembly of a mul- ticomponent transcription complex. Nucleic Acids Res. 18: $6871-6880$.

Klemsz, M., S. McKercher, A. Celada, C. Van Beveren, and R. Maki. 1990. The macrophage and B cell-specific transcription factor PU.1 is related to the ets oncogene. Cell 61: 113124.

Kristie, T.M., J.H. LeBowitz, and P.A. Sharp. 1989. The octamerbinding proteins form multi-protein-DNA complexes with the HSV alpha TIF regulatory protein. EMBO $/$. 8: 42294238.

Lillie, J. and M. Green. 1989. Transcription activation by the adenovirus Ela protein. Nature 338: 39-44.

McKnight, S. 1996. Transcription revisited: A commentary on the 1995 Cold Spring Harbor Laboratory meeting, "Mechanisms of eukaryotic transcription". Genes \& Dev. 10: 367 348.

McKnight, S. and Y. Yamamoto. 1992. Transcriptional regula tion. Cold Spring Harbor Laboratory Press, Cold Spring Harbor, NY.

Maniatis, T., S. Goodbourn, and J.A. Fisher. 1987. Regulation of inducible and tissue-specific gene expression. Science 236: 1237-1245.

Matsuyama, T., A. Grossman, H.-W. Mittrucker, D. Siderovski, F. Kiefer, T. Kawakami, C.D. Richardson, T. Taniguchi, S. Yoshinaga, and T. Mak. 1995. Molecular cloning of LSIRF, a lymphoid-specific member of the interferon regulatory factor family that binds the interferon-stimulated response element (ISRE). Nucleic Acids Res. 23: 2127-2136.

Nelson, N., M. Marks, P. Driggers, and K. Ozato. 1993. Interferon consensus sequence-binding protein, a member of the interferon regulatory factor family, suppresses interferon-induced gene transcription. Mol. Cell. Biol. 13: 588-599.

Olson, M., E. Scott, A. Hack, G. Su, D. Tenen, H. Singh, and M. Simon. 1995. PU.1 is not essential for early myeloid gene expression but is required for terminal myeloid differentiation. Immunity 3: 703-714.

Parker, D., K. Ferreri, T. Nakaijma, V. LaMorte, R. Evans, S. Koerber, C. Hoeger, and M. Montminy. 1996. Phosphorylation of CREB at ser-133 induces complex formation with CREB-binding protein via a direct mechanism. Mol. Cell. Biol. 16: 694-703.

Peterson, J.M., J.J. Skalicky, L.W. Donaldson, L.P. McIntosh, T. Alber, and B.J. Graves. 1995. Modulation of transcription factor ets-1 DNA binding: DNA-induced unfolding of an $\alpha$ helix. Science 269: 1866-1869.

Pongubala, J., S. Nagulapalli, M. Klemsz, S. McKercher, R. Maki, and M. Atchison. 1992. PU.l recruits a second nuclear factor to a site important for immunoglobulin $\kappa 3^{\prime}$ enhancer activity. Mol. Cell. Biol. 12: 368-378.

Pongubala, J., C. Van Beveren, S. Nagulapalli, M. Klemsz, S. McKercher, R. Maki, and M. Atchison. 1993. Effect of PU.1 phosphorylation on interaction with NF-EM5 and transcriptional activation. Science 259: 1622-1625.

Roberts, S. and M. Green. 1995. Dichotomous regulators. Nature 375: 105-106.

Rosenthal, N. 1987. Identification of regulatory elements of cloned genes with functional assays. Methods Enzymol. 152: 704-720.

Schindler, C. and I. Darnell. 1995. Transcriptional responses to polypeptide ligands: The JAK-STAT pathway. Annu. Rev. Biochem. 64: 621-651.

Scott, E., M. Simon, J. Anastasi, and H. Singh. 1994. Requirement of transcription factor PU.1 in the development of multiple hematopoietic lineages. Science 265: 1573-1577.

Serwe, M. and F. Sablitzky. 1993. V(D)| recombination in B cells is impaired but not blocked by targeted deletion of the im- 
munoglobulin heavy chain intron enhancer. EMBO $/$. 12: 2321-2327.

Sharf, R., A. Azriel, F. Lejbkowicz, S. Winograd, R. Ehrlich, and B.Z. Levi. 1995. Functional domain analysis of interferon consensus sequence binding protein (ICSBP) and its association with interferon regulatory factors. 1 . Biol. Chem. 270: 13063-13069.

Shin, M. and M. Koshland. 1993. Ets-related protein PU.1 regulates expression of the immunoglobulin J-chain gene through a novel Ets-binding element. Genes \& Dev. 7: 20062015.

Staudt, L. and M. Lenardo. 1991. Immunoglobulin gene transcription. Annu. Rev. Immunol. 9: 373-398.

Taniguchi, T., H. Harada, and M. Lamphier. 1995. Regulation of the interferon system and cell growth by the IRF transcription factors. J. Cancer Res. Clin. Oncol. 121: 516-520.

Thornton, A.M., R.M. Buller, A.L. DeVico, I.M. Wang, and K. Ozato. 1996. Inhibition of human immunodeficiency virus type 1 and vaccinia virus infection by dominant negative factor of the interferon regulatory factor family expressed in monocytic cells. Proc. Natl. Acad. Sci. 93: 383-387.

Veals, S., C. Schindler, D. Leonard, X.-Y. Fu, R. Aebersold, J. Darnell, and D. Levy. 1992. Subunit of an alpha-interferonresponsive transcription factor is related to interferon regulatory factor and myb families of DNA-binding proteins. Mol. Cell. Biol. 12: 3315-3324.

Veals, S., T. Santa Maria, and D. Levy. 1993. Two domains of ISGF3 $\lambda$ that mediate protein-DNA and protein-protein interactions during transcription factor assembly contribute to DNA-binding specificity. Mol. Cell. Biol. 13: 196-206.

Xu, Y., L. Davidson, F.W. Alt, and D. Baltimore. 1996. Deletion of the Igк light chain intronic enhancer/matrix attachment region impairs but does not abolish $\mathrm{VkJ}_{\kappa}$ rearrangement. Immunity 4: 377-385.

Yamagata, T., I. Nishida, T. Tanaka, R. Sakai, K. Mitani, M. Yoshida, T. Taniguchi, Y. Yazaki, and H. Hirai. 1996. A novel interferon regulatory factor family transcription factor, ICSAT/Pip/LSIRF, that negatively regulates the activity of interferon-regulated genes. Mol. Cell. Biol. 16: 12831294. 


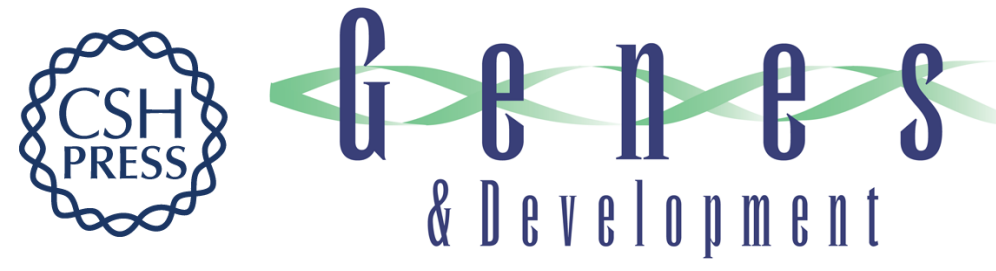

\title{
Pip, a lymphoid-restricted IRF, contains a regulatory domain that is important for autoinhibition and ternary complex formation with the Ets factor PU.1.
}

\author{
A L Brass, E Kehrli, C F Eisenbeis, et al.
}

Genes Dev. 1996, 10:

Access the most recent version at doi:10.1101/gad.10.18.2335

References This article cites 46 articles, 24 of which can be accessed free at:

http://genesdev.cshlp.org/content/10/18/2335.full.html\#ref-list-1

License

Email Alerting Service

Receive free email alerts when new articles cite this article - sign up in the box at the top right corner of the article or click here.

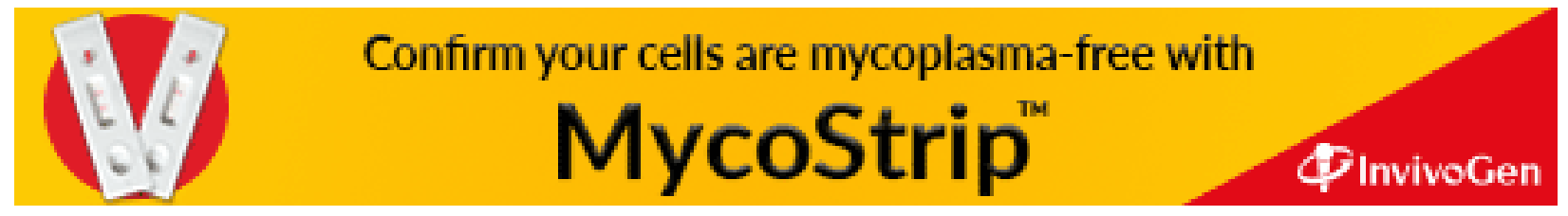

